\title{
Vestígios da memória e regressos em Isabela Figueiredo e Dulce Maria Cardoso
}

\author{
Tania Mara Antonietti Lopes \\ Universidade de São Paulo
}

\begin{abstract}
Resumo
A partir de uma análise do Caderno de memórias coloniais (2009), de Isabela Figueiredo, e de O retorno (2012), de Dulce Maria Cardoso, propõe-se uma leitura reflexiva, pelo viés da memória entrelaçada à ficção, de histórias que traduzem questões de subjetividade atreladas à idealização de Portugal durante o processo de descolonização. Nesse aspecto, importa mostrar ao leitor as estratégias que as autoras utilizam para reconstruir a memória por meio da ficção e, respectivamente, suas identidades em relação à metrópole. Como base teórica para nossa abordagem, utilizamos a perspectiva de Paul Ricoeur, em $A$ memória, a história, o esquecimento (2007).
\end{abstract}

Palavras-chave: memória; ficção; retorno; Isabela Figueiredo; Dulce Maria Cardoso.

\begin{abstract}
This article proposes an analysis of Caderno de memórias coloniais (2009), by Isabela Figueiredo, and $O$ Retorno (2012), by Dulce Maria Cardoso, as a reflexive reading, through the lens of memory intertwined with fiction, of stories that translate questions of subjectivity linked to an idealized view of Portugal during the decolonization process. In that regard, my main concern is to show the reader the strategies both authors use to reconstruct memory through fiction and, in particular, their identities in relation to the colonial power. As a theoretical basis for my approach, I take into account the perspective of Paul Ricoeur in A memória, a história, o esquecimento (2007).
\end{abstract}

Keywords: memory; fiction; return; Isabela Figueiredo; Dulce Maria Cardoso.

Recebido em: 29/07/19

Aprovado em: 16/11/19 
Atenha-se ao agora, ao aqui, por onde todo futuro submerge no passado...

James Joyce (apud Plath, 2017, p. 19)

Mas esta não pretende ser uma autobiografia comum. Só me permiti invocar a memória quando sei que as suas respostas possuíam algum grau de interesse...

Brontë (2018)

O tema que propomos para este artigo tem como elemento essencial a memória. Mas traz consigo questões que concernem a uma construção ideológica. E essa construção tem referências na história colonial. No Caderno de memórias coloniais, livro de Isabela Figueiredo, publicado em 2009, o espaço colonial se caracterizava pelo racismo, pela violência contra a mulher, entre outras questões decorrentes do contexto histórico e social de Moçambique. No romance de Dulce Maria Cardoso, publicado em 2012, ficam evidentes questões relativas à construção de identidade das personagens que retornam à metrópole e o que significa a metrópole. Tratase de textos que constituem uma pesquisa ${ }^{1}$ que tem como elemento principal a construção da memória, uma vez que o eixo de nossas reflexões se alinha ao modo como as autoras em questão desenvolvem, cada qual a seu modo, narrativas do regresso a partir de vestígios há muito silenciados e que na última década tem ganhado certa evidência.

Portanto, devemos justificar nossa escolha no que se refere ao embasamento teóricocrítico. O objetivo foi compreender "como" são abordadas as relações de identidade (muito mais a ver com subjetividade) e a condição de retornado (entendido no viés ideológico) em construções ficcionais. Optamos por uma abordagem de perspectiva filosófica, levando sempre em consideração as técnicas narrativas escolhidas para apresentar tais relações. E para tentar lançar alguma luz sobre esse "como", iniciamos uma investigação a partir de duas perguntas importantes: “De que há lembrança? De quem é a memória?” (RICOEUR, 2007, p. 23).

$\mathrm{Na}$ esteira da fenomenologia husserliana, essas são perguntas essenciais quando o tema se concentra na questão da Memória. Em relação ao Caderno de memórias coloniais, tentamos compreender de que forma a autora manuseia a memória para construir a sua narrativa. $\mathrm{E}$ lançar mão da proposta de Paul Ricoeur (2007) se mostrou um caminho viável para a reflexão. Convenhamos que o texto de Isabela Figueiredo abarca o conceito de memória e promove a discussão mais ampla de seu uso, pois tratamos de uma autora que articula memórias "verdadeiras" com o processo ficcional. É um trabalho duplo, que nos obriga a lembrar que se trata de uma pretensão definir o estatuto de "verdade" da memória. Não é esse o caso. Pois

\footnotetext{
${ }^{1}$ Este texto, apresentado no I Seminário do Grupo de Pesquisa Colonialismo e Colonialismo em Português, em março de 2019, na FFLCH-USP, reproduz parte de minha pesquisa de Pós-Doutoramento, em andamento no Programa de Literatura Portuguesa (DLCV - FFLCH-USP), com bolsa do PNPD desde 2018.
} 
estamos lidando com ficção também, e nesse aspecto adentramos o âmbito da imaginação, o que nos leva a pensar na seguinte afirmação:

É sob o signo da associação de ideias que está situada essa espécie de curto-circuito entre memória e imaginação: se essas duas afecções estão ligadas por contiguidade, evocar uma - portanto, imaginar - é evocar a outra, portanto, lembrar-se dela. Assim, a memória, reduzida à rememoração, opera na esteira da imaginação. (RICOEUR, 2007, p. 25)

Isso que é muito propício para o nosso pensamento, pois quando falamos de imaginação, somos remetidos para a ficção. E aqui tratamos um livro, o de Isabela Figueiredo, em que na memória se mistura também a imaginação. Essa confusão não é incomum e é bem-vinda, porque possibilita a investigação no campo ficcional, valorizando-o inclusive, uma vez que a ficção opera a partir do real. O romance de Dulce Maria Cardoso confirma isso, e não é preciso esforço para perceber que a memória é nosso acesso ao passado. Logo, é nosso acesso ao real. Considerando puramente o tema da memória, o diálogo que observamos é muito produtivo entre as obras de Isabela Figueiredo e Dulce Maria Cardoso.

Retomando Ricoeur (2007), chama-nos a atenção - quando pensamos no estatuto de "verdade" da memória - o que ele postula sobre uma ideia diretriz que dissocia imaginação e memória:

É na corrente [da] tradição de desvalorização da memória, nas margens de uma crítica da imaginação, que se deve proceder a uma dissociação da imaginação e da memória, levando essa operação tão longe quanto possível. Sua ideia diretriz é a diferença, que podemos chamar de eidética, entre dois objetivos, duas intencionalidades: uma, a da imaginação, voltada para o fantástico, a ficção, o irreal, o possível, o utópico; a outra, a da memória, voltada para a realidade anterior, a anterioridade que constitui a marca temporal por excelência da "coisa lembrada", do "lembrado" como tal. (p. 25-26)

Partir desse pressuposto é bem pertinente, principalmente se levarmos em consideração, no caso da imaginação, que essa diferença proposta por Ricoeur pode ser questionável. Como dissociar imaginação e memória? Ele considera que imaginação seja algo inventado. Mas a invenção parte de onde? E, de um aspecto geral, a memória? Não há algo de imaginação nela também? Principalmente se transitamos num campo em que realidade e imaginação se misturam. Por diversas vezes, Ricoeur (2007, p. 27) nos remete à teoria platônica, mas é Aristóteles que torna a ideia mais concreta e declara que "a memória é passado". Essa afirmação serve de guia para a exploração de Ricoeur e, de certo modo, funciona como um guia para a nossa leitura.

Torna-se evidente que o trabalho com a imaginação tem relação com a necessidade humana de preencher as falhas da memória, consciente ou inconscientemente. Falhas que podemos atribuir ao esquecimento. O problema do esquecimento é colocado desde o início 
como "apagamento dos rastros e como falta de ajustamento da imagem presente à impressão deixada como que por um anel de cera. [...] desde esses textos fundadores, a memória e a imaginação partilham o mesmo destino". Essa situação torna mais evidente a afirmação de Aristóteles de que "a memória é tempo" (RICOEUR, 2007, p. 27).

No que diz respeito aos espaços vazios da memória, o "que está em jogo é o estatuto do momento da rememoração, tratada como um reconhecimento de impressão. A possibilidade da falsidade está inscrita nesse paradoxo" (RICOEUR, 2007, p. 30). Aqui pensamos no fato de a memória humana não ser confiável totalmente. Mas isso não desqualifica a ficção que consideramos. Em relação ao Caderno de memórias coloniais, remete-nos a uma pergunta que o filósofo apresenta:

Poderia a relação com o passado ser apenas uma variedade de mimesis? Essa confusão não deixará de nos acompanhar. Se nossa dúvida tem fundamento, existe o risco de a ideia de "semelhança fiel", própria da arte eicástica, ter fornecido mais uma máscara do que uma escala na exploração da dimensão veritativa da memória. (RICOEUR, 2007, p. 32)

Tanto no Caderno de memórias coloniais quanto n'O retorno, ainda pensando na relação entre memória e imaginação, é necessário apontar que "[t]oda lembrança é acompanhada pela noção de tempo" (MUGNIER apud RICOEUR, 2007, p. 35) e "nós nos lembramos daquilo que não está presente" (RICOEUR, 2007, p. 36). No caso dos retornados (consideremos aqui as personagens), a iniciativa da busca depende de sua possibilidade, pois o ponto de partida está em poder de quem explora o passado. Nesse caso, confirma-se que a noção de distância temporal é inerente à essência da memória. Nos dois livros, presenciamos o papel que a evidência dos lapsos temporais enfatiza, ou seja, o lado racional da memória, uma vez que a busca constitui uma espécie de raciocínio. O exercício da memória se manifesta de modos diferentes nas narrativas.

No Caderno de memórias coloniais, a memória subjetiva e familiar da narradora e protagonista de Isabela Figueiredo é apresentada por uma personagem muito próxima do que poderíamos considerar como autoficção, uma vez que possibilita uma aproximação das experiências vividas, ou melhor, revisitadas, por uma filha de retornados nascida em Moçambique. A consciência do não pertencimento e o apego à memória de um espaço que não existe mais, agindo como elemento que possibilita a certeza de que tudo o que foi vivido existiu, aproxima a narrativa do Caderno de memórias coloniais do discurso produzido por Rui, n'O retorno.

Há pouco mais de quatro décadas da Revolução dos Cravos, a elaboração da memória daqueles que foram obrigados a retornar é muito cara e necessária, pois se trata de uma história silenciada, mas possível de ser articulada: 
[...] a experiência da Guerra Colonial e a saída de Portugal de África foi convertida numa linha narrativa que se foi transformando numa fragmentária reescrita dos últimos dias coloniais de Portugal. Elaborada sob a metáfora do regresso e realizando inicialmente uma função individual e terapêutica, esta linha veio romper com "o vazio historiográfico (Vecchi 2000:394) e o silenciamento social e político que o regime, saído do 25 de Abril, fez sobre o acontecimento. (RIBEIRO, 2006, p. 43)

Embora se queira esquecer e fazer esquecer a herança vergonhosa deixada pela Guerra Colonial, "como se fosse possível fazê-la desacontecer, como se tudo tivesse sido um engano [...] um equívoco, uma história de mal-entendidos" (RIBEIRO, 2006, p. 44), ela veio à tona com os retornados. Ainda subsistem rastros da memória colonial. A partir dessas narrativas que mencionamos, torna-se necessário saber quem são e o que dizem os sujeitos marginalizados pela ordem colonial-patriarcal que colocam em discussão. Esses sujeitos se manifestam na forma do relato de memória, seja ela primária ou secundária (como preferimos classificar), para construir uma nova narrativa.

Daí a relação comprometida e tensa que esta literatura apresenta entre uma falha da memória colectiva e um excesso de memória pessoal [...] entre a história e o testemunho elaborado mais ou menos romanescamente. Da leitura dessa literatura, fica a imagem de um Portugal em acelerado processo de fragmentação e esvaziamento, o que explica a tematização obsessiva, por parte dos narradores ou sujeitos líricos, da sua identidade, num exercício de reencontrar o seu rosto e o sujeito português [...]. (RIBEIRO, 2006, p. 45)

As populações que optaram por Portugal como terra de "retorno" fizeram uso de laços familiares que ainda existiam para prover o acolhimento na metrópole, como é exemplificado nos livros. Portanto, é comum percebermos, a partir da leitura dessas narrativas, que a maior parte das famílias chegou destituída, uma vez que deixou para trás bens materiais, impedida de trazer consigo mais do que a pequena quantidade de suas economias.

Inevitavelmente, o declínio do "império" se mostrou evidente, sobretudo quando se assistia à evacuação de 260 mil indivíduos de Angola entre julho e novembro de 1975. Em Moçambique, o contingente mais intenso decorreu a partir dos acontecimentos de 7 de setembro de 1974, mencionados de modo obsessivo no Caderno de memórias coloniais.

Portanto, trata-se de um "retorno" à pátria que, na realidade, nunca pertenceu àqueles que migraram. Nesse ponto, expliquemos o que significa essa "classe" que, conforme Peralta e Oliveira (2016, p. 184-185), surgiu como uma resposta do Estado português ao movimento migratório em massa das ex-colônias. Criou-se, a partir dessa atuação, o Instituto de Apoio ao Retorno de Nacionais (IARN), consagrando, assim, em 1975, o substantivo "retorno", derivando daí "retornado". 
Em muitos casos, essa expressão se revela como uma categorização problemática. Pois, considerando que semanticamente retorno é o "ato ou efeito de retornar"; "regresso no espaço ou no tempo"; "volta de uma peça móvel ao seu ponto de origem"² — só para mencionar as acepções relevantes para o que pretendemos esclarecer - , muitas pessoas incluídas nessa categoria não condizem com a classificação. Isabela Figueiredo é um exemplo: uma vez que nasceu em Moçambique, como rotular a autora como retornada? A melhor definição seria de fato "refugiada" ou "desalojada", como muitos se autodefiniram? A resposta ela oferece em seu Caderno. Rui e sua irmã (O retorno), assim como muitos de seus amigos, também não se "enquadram" nessa categoria de retornados.

De todo modo, permanece o termo "retornado", por todo o significado que carrega. Assim, com a identidade violentada, adaptada à vida na África, os retornados empreendem uma viagem a contragosto, levada por forças históricas e em condições extremamente precárias. É possível encontrar o tom crítico e demolidor sobre o sonho imperial nos livros em questão, exemplificado aqui em uma pergunta: "Então a metrópole afinal é isto?" (CARDOSO, 2013, p. 65). A "agonia pessoal" como "o espelho de uma agonia colectiva" é delineada diegeticamente no Caderno de memórias coloniais, tornando clara a missão que se autoimpôs a autora, pois coube à geração dos filhos daqueles que voltaram à metrópole recontar essa história em tom mais subjetivo, em muitos momentos, confidencial (FIGUEIREDO, 2018za, p. 9).

Talvez seja uma consciência dolorosa do não pertencimento que torne também doloroso o testemunho da memória familiar, como postula Figueiredo, ao revelar que seu Caderno de memórias coloniais "tem uma vida própria", abre-se como uma janela para onde o vento traz "intacto o ambiente do passado, descongelado, inteiro e autêntico, com os seus ruídos e odores", sem deixar, contudo, de ser uma ficção "para dizer a verdade, esse outro grande paradoxo da literatura" (FIGUEIREDO, 2018a, p. 10). O que nos remete a uma tendência de muitos autores em abordar a memória a partir "de suas deficiências, até mesmo de suas disfunções" (RICOEUR, 2007, p. 40). Trata-se de uma preferência pela memória "certa", ideia essa que se origina pela convicção de que a memória é o único recurso que temos para nos referirmos ao passado. Desse modo, uma ambição (ou pretensão) se vincula à memória: a de ser fiel ao passado.

Se podemos acusar a memória de se mostrar pouco confiável, é precisamente porque ela é o nosso único recurso para significar o caráter passado daquilo de que declaramos nos lembrar. Ninguém pensaria em dirigir semelhante censura à imaginação, na medida em que esta tem como paradigma o irreal, o fictício, o possível e outros traços que podemos chamar de não posicionais. (RICOEUR, 2007, p. 40)

\footnotetext{
${ }^{2}$ ORIGEM. In: GRANDE DICIONÁRIO Houaiss da língua portuguesa. Disponível em: https://houaiss.uol.com. br/pub/apps/www/v3-3/html/index.php\#1. Acesso em: 16 maio 2019.
} 
Na esteira desse pensamento, que diferencia memória e imaginação, é possível conceber um paralelo entre memória e história e discutir sobre a ideia de que "o testemunho constitui a estrutura fundamental de transição entre a memória e a história” (RICOEUR, 2007, p. 41). Como leitores do Caderno de memórias coloniais, podemos esperar que os fatos relatados coincidam com o testemunho, mas não nos esqueçamos de que, ainda assim, trata-se de um trabalho literário. Nesse aspecto, podemos conceber a memória como filtro seletivo e construtor. "La mémoire est une construction" (FRAISSE, 1967, p. 168, apud CHAGAS, 2003, p. 176), por isso falível em sua tentativa de ressuscitar fatos, acontecimentos ou pessoas de forma fidedigna, uma vez que, nessa construção, o vestígio de uma lembrança é muito frágil. Desse modo, a partir de

[...] um olhar que se guia pelo desejo de retorno ao passado e a esse espaço ao qual se sentem intrinsicamente unidos, que o leitor será conduzido, inevitavelmente, a um espaço ocupado pela voz da memória. Será através dela que é reposta a ordem que cada um desejava ter experimentado, sobrepondo-a ao caos frustrante vivenciado. (CHAGAS, 2003, p. 176)

Nas epígrafes de seu livro, Isabela Figueiredo oferece as pistas como indicativas de leitura. A primeira faz referência ao pai (a quem dedica o livro), como uma justificativa para as páginas que se seguirão.

De cada vez que abria uma gaveta ou espreitava para dentro de um armário, sentia-me como um intruso, um ladrão devassando os locais secretos da mente de um homem. A todo o momento esperava que o meu pai entrasse, parasse incrédulo a olhar para mim e me perguntasse que raio é que eu pensava que estava a fazer. Não me parecia justo que ele não pudesse protestar. Eu não tinha o direito de invadir a sua privacidade. (AUSTER, apud FIGUEIREDO, 2018a, p. 29)

A segunda está diretamente relacionada à memória como construção.

A memória humana é um instrumento maravilhoso mas falível.

$[\ldots]$

As recordações que jazem dentro de nós não são gravadas em pedra; não só têm a tendência para se apagarem com os anos, como também é frequente modificarem-se, ou inclusivamente aumentarem, incorporando delineamentos estranhos. (LEVI apud FIGUEIREDO, 2018a, p. 29)

Essa última epígrafe vem ao encontro do que Ricoeur (2007) classifica como "memória do esquecimento". Ao se referir a Santo Agostinho, o filósofo lança mão do esforço de recordação para falar que a busca da lembrança comprova uma das principais finalidades do ato de memória, que é lutar contra o esquecimento, arrancar desse esforço fragmentos de 
lembrança. Esse "dever de memória consiste essencialmente em dever de não esquecer. Assim, boa parte da busca do passado se encaixa na tarefa de não esquecer" (RICOEUR, 2007, p. 48).

Isso se encaixa tanto no Caderno de memórias coloniais quanto n'O retorno. O medo de esquecer, ou melhor, a necessidade de não se esquecer, de precisar se lembrar, tem mais a ver com a subjetividade, com a existência, porque a história é entendida nas entrelinhas. No caso de Dulce Maria Cardoso, a epígrafe, de Dulce María Loynaz, é apresentada no final do romance (promovendo uma inversão): "Las cosas que se mueren/ no se deben tocar" (CARDOSO, 2013, 22,p. 268).

Essa frase é repetida por Glória, mãe de Rui, e se não devemos tocar o que está morto, talvez tenhamos que buscar respostas para as coisas que não podem morrer, que não devem ser esquecidas. Além de reforçar a ideia do tabu português acerca dos retornados, demonstra um convite à reflexão sobre os questionamentos colocados na história, e que não podem ser esquecidos.

Toda a narrativa é marcada por um movimento pendular entre dois tempos e dois lugares e, assim, sob a batuta da voz do narrador, vamos oscilando constantemente entre o antes e o depois do regresso, entre o cá (metrópole) e o lá (Angola), num circuito iterativo de vivências e recordações. (VALADARES, 2011, p. 93)

Como uma proposta de reflexão sobre a perda, a autora não espera catarse dos leitores, mas sim um distanciamento reflexivo: "Eu andei à procura de uma proposta de reflexão que me servisse. A ideia é de perda, é de estar à deriva. É a perspectiva de o futuro ser negro" (CARDOSO apud BARROS, 2016, p. 195). Essa perspectiva, se retomarmos a primeira epígrafe deste artigo, afirmada por James Joyce: “Atenha-se ao agora, ao aqui, por onde todo futuro submerge no passado...” (apud PLATH, 2017, p. 19), veremos que também remete à ideia de movimento pendular, porque o futuro depende do passado e o passado só se resgata pela memória. Nesse sentido, considerando a valorização da subjetividade assegurada, nesse caso, pelo testemunho dos sentimentos e experiências que se constituem num processo social de construção de memória, percebemos que os relatos oferecidos nos dois livros dão voz a uma classe (os retornados) e proporcionam, de certo modo, a recuperação da história desses sujeitos em pequena escala.

No Caderno de memórias coloniais, presenciamos um trabalho de recriação da memória com o auxílio dos processos de criação fíccional.

[...] Existe o meu pai e a personagem. Fico com o primeiro.

O Caderno existe por ele e para ele. Foi uma das minhas lições, e esta obra é a carta que quis deixar-lhe.

Quero acreditar que ao mandar-me para Portugal, em 1975, onde nasceu, donde saiu com o objetivo de não regressar, o meu pai delegou nesta terra, para mim desconhecida, ascendente e poder para me salvar. 
Resta-me amar com exigência e desespero a terra negra à qual me confiou.

Nela busco o mapa para o tesouro que aqui escondeu, e que um dia encontrarei. (FIGUEIREDO, 2018a, p. 12)

Na reelaboração dessa memória, todos os caminhos para o passado atravessam tensões e conflitos em que história e esquecimento são experiências independentes. Nesse passado, o que fica evidente na narrativa é que, o que a autora trata como "intriga pós-colonial" não se resolve e nem se explica na pergunta que coloca: "se todos vivemos o mesmo, no mesmo local e época, como posso só eu ter visto e sentido o que escapou aos outros? Porque foi escolha minha, prioritária, lembrá-lo?" (FIGUEIREDO, 2018a, p. 8).

Talvez, o mais viável para tornar mais leve a condição de retornada e tudo o que isso implica, seja mesmo eleger a escrita como modo de sobrevivência, afirmação que se revela de modo mais enfático em $A$ gorda, romance considerado pela própria autora como um desenvolvimento mais elaborado de seu Caderno. E não seria esse modo de sobrevivência o elemento que concretiza a memória? A memória do que passou e a memória que permanece, na forma de escrita, para as futuras gerações.

Nesse sentido, o esquecimento como contraponto da memória, entendido também como silêncio, pode aparecer tanto como assunto quanto como estrutura na obra de Dulce Maria Cardoso.

Em seu romance, o silêncio é percebido quando se trata da volta do pai de Rui: “[...] o silêncio do pai faz com que as cicatrizes contem mais coisas terríveis do que as que o pai poderia alguma vez contar [...]" (CARDOSO, 2013 p. 251). Isso pode ser interpretado como "tentativa de preencher as lacunas deixadas pela ruína do império português" (LESSA, 2015, p. 7). Além disso, o silêncio também faz parte da estrutura do romance, por meio de "rupturas na sintaxe narrativa" (VALADARES, 2011, p. 95): é o que acontece quando Rui narra o paradeiro do pai no final de cada um dos dezoito parágrafos do segundo capítulo. Trata-se de informações fragmentadas, assim como a memória que Rui nos oferece desse episódio. Esse silêncio em fragmentos pode tanto dramatizar a decepção automática de Rui quanto fazer referência a um passado que não se pode mais tocar — que foi perdido e é irrecuperável.

Nessa linha, o romance pode também ser interpretado como tentativa de preenchimento do vazio que o silêncio ocupa no discurso histórico português:

Se para a geração dos pais que protagonizaram o retorno este foi vivido exclusivamente como perda traumática, coube à geração dos filhos e filhas ultrapassar o silêncio que se cola ao corpo dos traumatizados, furar esse silêncio, dar testemunho do que viveram seus pais, os quais se recusaram a falar sobre sua experiência. (SCHMIDT, 2016, p. 129)

O único capítulo do romance que não apresenta o fluxo de consciência de Rui é o quarto, que traz um monólogo longo, de sete páginas, proferido pela diretora do hotel, que parece falar 
por Portugal inteiro e reflete, sobretudo, a condição do retornado (LESSA, 2015, p. 6). Mas é no fluxo de consciência que percebemos o exercício da memória, cuja "veracidade" é questionada por mecanismos retóricos como a repetição nas frase de Rui: "Um quarto pode ser uma casa e este quarto e esta varanda de onde se vê o mar é a nossa casa" (CARDOSO, 2013 p. 165). A repetição demonstra a tentativa de Rui de se convencer de uma verdade que lhe foi imposta.

Assim, aproveitamos para explorar aquilo que mencionamos sobre uma questão que o tema da memória possibilita na análise desses livros, como a construção de identidade, representada em $O$ retorno pelo não pertencimento de Rui. Trata-se de um elemento mais metafórico que literal. O lá (Angola) e o cá (Portugal) são espaços empíricos; seu passado é Angola, seu presente, repleto de incertezas, é o hotel, e seu futuro é uma constante expectativa (ir ao Brasil? À América?), que só tem rumo certo com o retorno do pai. Como vemos, o exercício com a memória é duplo e constante. E nesse exercício, a própria autora articula as suas memórias, pois as personagens de Dulce Maria Cardoso, como ponto de partida, têm origem na realidade.

Houve de fato um Rui real que não tem nada a ver com o Rui do livro. Houve um Rui real, que perdeu os irmãos, que foram assassinados. E escolher uma personagem masculina e chamá-la de Rui no livro foi uma forma de homenagem, não só àquele Rui, mas ao que aquele Rui representava. [...] Houve mesmo uma empregada de uma vizinha, que eu nunca a conheci sequer, mas que eu sempre escutava a chamarem por Maria da Guia. [...] Mas só eu faço parte do real. [...] A única que é real. (CARDOSO apud MACHADO, 2014, p. 4)

Dulce Maria Cardoso reivindica o estatuto de autobiografia para a sua escrita, aproximando-se, dessa forma, de Isabela Figueiredo:

Acredito que toda a escrita é autobiográfica. Às vezes dou conta disso outras não, mas tudo é autobiográfico. Como vivência ou pensamento. [...] O Rui já estava em mim e continuará em mim. Inteiro. O Rui para mim é tão real como qualquer pessoa de carne e osso. (CARDOSO apud MACHADO, 2014, p. 1)

Pela escrita, as duas autoras portuguesas tiveram um mesmo papel, isto é, "ultrapassar o silêncio que se cola ao corpo dos traumatizados" (SCHMIDT, 2016, p. 129) ao preencher o vazio histórico deixado pelo colonialismo. Foi também o papel de outros autores portugueses, como Antonio Lobo Antunes, dar fim ao silêncio que havia décadas feria a dignidade dos retornados.

No caso de Isabela Figueiredo, a partir da tarefa de reconstrução dos vestígios, dos rastros que permaneceram de suas lembranças, sintetiza-se o desejo de julgamento, por um lado e, por outro, absolvição quando se refere ao pai como símbolo do colonialismo e percebemos, nas afirmações da autora, o exercício contínuo que se estabelece na construção entre memória e ficção: 
É também mais fácil construir o que aceitamos recordar. Essa narrativa torna-se a realidade, a única em que acreditamos e que defendemos.

A História enfrenta sempre esse grande óbice, que cabe aos investigadores ultrapassar: o silêncio sobre o que muito se calou ou escondeu. (FIGUEIREDO, 2018a, p. 8)

Reinventando a memória que se adapta pelo trabalho de reescrita, Isabela Figueiredo realiza uma narrativa veemente, perspicaz, e recupera de uma maneira muito sagaz o tema do retorno e, nesse âmbito, pensamos na necessidade da memória em deter um espaço que não existe mais fisicamente. Ricoeur se refere a isso como fenômenos que não nos afastam "da esfera da intencionalidade" (2007, p. 57). Para exemplificar o que afirma, ele ancora suas lembranças em épocas e lugares para onde viajou, associando-os a sentimentos. Mas é do presente que ele evoca os lugares por onde passou:

Lembro-me da extensão daquela paisagem marinha que me dava o sentimento da imensidão do mundo. E, quando da visita àquele sítio arqueológico, eu evocava o mundo cultural desaparecido ao qual aquelas ruínas remetiam tristemente. Como a testemunha numa investigação policial, posso dizer sobre tais lugares que "eu estava lá”. (RICOEUR, 2007, p. 57)

Aqui é inevitável pensar no que Rui declara, como que para afirmar a sua existência, no último parágrafo de $O$ retorno:

Um avião risca o céu a direito. Silencioso. Como um giz preguiçoso nas mãos invisíveis de deus. Noutro tempo ter-lhe-ia respondido daqui de baixo. Talvez ainda responda. Noutro tempo ter-lhe-ia escrito, talvez ainda escreva, em letras bem grandes a todo o comprimento do terraço para que não possa deixar de ver-me, eu estive aqui.

Eu estive aqui. (CARDOSO, 2013, p. 267)

A partir do excerto, podemos inferir que "as 'coisas' lembradas são intrinsicamente associadas a lugares" (RICOEUR, 2007, p. 57). Daí a ideia de "lugares de memória", que funcionam como indícios de recordação, pois oferecem apoio à memória que falha. Tratase de uma luta contra o esquecimento e de uma "suplementação" da memória morta. Os lugares "permanecem como inscrições, monumentos, potencialmente como documentos, enquanto as lembranças transmitidas unicamente pela voz voam, como voam as palavras" (RICOEUR, 2007, p. 58).

Dito desse modo, os lugares de memória seriam os guardiões da memória pessoal e coletiva, mesmo não ocupando um lugar físico. No caso de Isabela Figueiredo, protagonista e narradora, a filha retornada exerce voz narrativa que ora se mistura, ora se distancia da autora. A voz refletida em primeira pessoa busca desvendar, pela percepção da menina que viveu os episódios relatados o que somente a compreensão adulta tem condições, posteriormente, de 
elaborar. Logo na abertura do Caderno, a narradora introduz seu relato por meio de um sonho que tem como função conduzir o leitor para uma direção específica, em que é necessário abrir os olhos para receber a "verdade" a ser revelada.

Disse alto, com voz forte e jovial, muito perto da minha cabeça:

— Olá!

Era um olá grande, impositivo, ao qual me seria impossível não responder. Reconheci a sua voz, e, ainda no sono, pensei, não podes ser tu, tu já morreste.

E abri os olhos. (FIGUEIREDO, 2018a, p. 31)

A partir de então, delineia-se um relato em que o discurso da memória, entendido aqui como as experiências da menina, trazendo o passado para o presente, adapta-se à releitura da narradora adulta. A distância entre o que viveram os pais e o que relataram os filhos dos retornados mostra que o tema da memória não só possibilita uma reflexão sobre a complexidade das emoções humanas, como também evita que o conhecimento da subjetividade da condição humana sirva como elaboração de meios eficazes de controle e dominação, pois o testemunho que transita entre a memória familiar e o olhar sobre o retorno como trauma coletivo acaba por não poupar os portugueses de sua responsabilidade histórica. Nesse caso, onde estão as informações que nos dão o acesso confiável ao que aconteceu? Na literatura? Em parte, sim.

A ideia, com essa leitura, foi propor uma reflexão sobre como a memória é evocada em cada livro, apontando, quando é possível, o que se ramifica das questões que esse tema possibilita. Nosso trabalho é apenas uma centelha do que pode ser explorado a partir daqui.

\section{Referências}

BARROS, B. M. Seres estranhos: personagens em desencontros em romances de Dulce Maria Cardoso. In: CARDOSO, J. A. et al. (orgs.). Literatura, linguagem e mídia. Águas de São Pedro: Livronovo, 2016. p. 192-198.

BRONTË, Charlotte. Jane Eyre. Edição bilíngue português-inglês. Tradução e notas de Doris Goettens. São Paulo: Landmark, 2018. E-book.

CARDOSO, Dulce Maria. O retorno [2012]. 2. ed. Rio de Janeiro: Tinta-da-china Brasil, 2013.

CHAGAS, Maria Manuela Duarte. Da multiplicidade de vozes narrativas à incomunicabilidade. O esplendor de Portugal - uma narrativa plurivocal. In: CABRAL, Eunice; JORGE, Carlos J. F.; ZURBACH, Christine (orgs.) A escrita e o mundo em António Lobo Antunes. Lisboa: Universidade de Évora e Dom Quixote, 2003. p. 171-185.

FIGUEIREDO, Isabela. Caderno de memórias coloniais [2009]. São Paulo: Todavia, 2018a. . A gorda. São Paulo: Todavia, 2018 b.

LESSA, C. F. As coisas que morrem não se devem tocar: uma leitura de $O$ retorno, de Dulce Maria Cardoso. Mulheres e Literatura, Rio de Janeiro, v. 14, p. 1-9, 2015. 
MACHADO, Alleid Ribeiro. Dulce Maria Cardoso e Júlia Nery: olhares em torno da diáspora portuguesa em França e África. Entrevista. Desassossego, São Paulo, v. 12, p. 95-119, 2014.

PERALTA, Elsa; OLIVEIRA, Joana Gonçalo. Pós-memória como herança: fotografia e testemunho do "retorno" de África. Configurações, Braga, v. 17, p. 181-197, 2016. Disponível em https://journals.openedition.org/configuracoes/3290. Acesso em: 7 out. 2018.

PLATH, Sylvia. Os diários de Sylvia Plath: 1950-1962. 2. ed. Organização: Karen V. Kukil. Tradução: Celso Nogueira. São Paulo: Biblioteca Azul, 2017.

RIBEIRO, Margarida Calafate. As ruínas da casa portuguesa em "Os cus de Judas" e em $O$ esplendor de Portugal, de Antonio Lobo Antunes. In: SANCHES, Manuela Ribeiro (org.). Portugal não é um país pequeno: contar o Império na pós-colonialidade. Lisboa: Livros Cotovia, 2006.

RICOEUR, Paul. Da memória e da reminiscência. Memória e imaginação. A memória, a história, o esquecimento. Tradução: Alain François et al. Campinas: Editora da Unicamp, 2007. (p. 21-70).

SCHMIDT, Simone Pereira. Uma viagem longa demais, um retorno devastador. Revista do Núcleo de Literatura Portuguesa e Africana da UFF, Niterói, v. 8, n. 16, jul. 2016.

VALADARES, L. M. C. B. O retorno: uma viagem de formação e refundação de identidade. Forma Breve, Aveiro, p. 91-100, 2011.

\section{Minicurrículo}

Tania Mara Antonietti Lopes é graduada em Letras pela Universidade Estadual Paulista Julio de Mesquita Filho, UNESP - Araraquara (2005). Realizou mestrado (2007) e doutorado (2011) na mesma instituição, com bolsa CAPES/CNPq e pós-doutorado (2016) com bolsa FAPESP, especializando-se na obra de José Saramago. Atualmente, é pesquisadora no Programa de Literatura Portuguesa (DLCV), na FFLCH-USP, onde desenvolve pesquisa sobre os processos de representação da memória na obra de Isabela Figueiredo, debruçando-se sobre temas inerentes ao pós-colonialismo, como o imperialismo português e os retornados. É membro do Grupo de Pesquisa Colonialismo e Pós-Colonialismo em Português. 